\title{
Mediated Storytelling Practices and Productions: Archival Bodies of Affective Evidences
}

\author{
JAMIE A. LEE, University of Arizona
}

\begin{abstract}
Through hands-on work collecting digital video oral histories for the Arizona Queer Archives, bodies and bodies of knowledge in ongoing affective states of simultaneous becoming and unbecoming can be observed and encountered. Both interviewing and storytelling techniques in select oral histories are considered here to stress the salient and affective processes of mediation and (un)becoming that unfold in front of and behind the camera as part of the production of digital archival stories and subsequent access to streaming technologies. In order to explore the details of archival production, the oral history interview is understood here as a space of both intimate and public storytelling - an affective assemblage. This paper introduces archives as affective multimodalities that work to tenderly hold and structure bodies, technologies, and stories especially as these come together and apart in states of (un)becoming.
\end{abstract}

\section{KEYWORDS}

Archives, Bodies, Oral histories, Affect, Evidence

\begin{abstract}
'It may be that here in our provisional world of dualities and oppositional pairs: black/white, good/evil, male/female, conscious/unconscious, Heaven/Hell, predatory/prey, we compulsively act out the drama of our beginning, when what was whole, halved, and seeks again its wholeness' (Winterson 1997, 6).
\end{abstract}

The digital video camera rests on its tripod. Legs spread as stable and sturdy surveillance. Wireless microphone receiver perches on top tracing the $\mathrm{MHz}$ transmitting sound-breathing and counting and more breathing. Three-CCD camera acquiring and absorbing what it points to. At this moment the world pivots around this one point. Do not call it gravity or even centrifugal force $\left(F_{c}=m v^{2} / r\right.$, where $F_{c}=$ centrifugal force, $m$ $=$ mass, $\mathrm{v}=$ speed, and $\mathrm{r}=$ radius $)$. But do recognize that there is a force, a generative force of movement that pulls and pushes simultaneously. At the interstices of interviewer and interviewee, the coming together and coming apart produces and is produced by tensions, powers, and proximities. Intimate and public spaces are stitched together at this pivot. Two seemingly distinct gradations of intimacy that stand opposing but become an in-between space of mediated navigation that creates imbricating affectivities. Pushing. Pulling.

Through hands-on work collecting digital video oral histories for the Arizona Queer Archives, bodies and bodies of knowledge in ongoing affective states of (un)becoming-

the simultaneous becoming and unbecoming - can be observed and encountered. Both interviewing and storytelling techniques in select oral histories are considered here to 
stress the salient and affective processes of mediation and (un)becoming that unfold in front of and behind the camera as part of the production of digital archival stories as well as subsequent access to streaming technologies. In order to explore the details of archival production, the oral history interview is understood here as a space of both intimate and public storytelling — an affective assemblage in which the interviewer and interviewee come together and are moved in indeterminate ways. In this article, I first define the key terms and concepts that support my project to introduce archives as affective multimodalities that work to tenderly hold and structure bodies, technologies, and stories especially as these come together and apart in states of (un)becoming. I then consider both interviewing and storytelling techniques in oral history productions to stress the processes of negotiating and mediating histories, memories, contexts, and contemplations that unfold.

The digital video camera stands between interviewer and interviewee. The camera lens points one way. Interviewer sees interviewee through the viewfinder, a rectangular screen containing the human subject in a medium shot slightly left of center with the wall behind out of focus, but with the fuzzy family photos, that distinct painting the interviewer asked the interviewee about upon first entering the room, and the vase of flowers with reds, purples, and baby's breath. A montage of colors propping the human subject up in their seat with all eyes (one camera) on said subject. A distance behind and a distance between. A focal depth of field and a haptic depth of feeling. Bodily convergences and divergences as the interviewer pushes the red RECORD button.

'We are rolling,' the interviewer announces.

\section{Concepts \& Terminologies}

To support my argument that mediating storytelling techniques emerging from the oral history interview influence the archives as affective and (un)becoming bodies of evidence, I start with archives and bring together a number of key concepts with my specific focus on (un)becoming.

\section{Archives}

Following Chicana feminist scholars Chela Sandoval ${ }^{1}(2000,10)$, Aimee Carrillo Rowe and Adela C. Licona ${ }^{2}(2005,11)$, I know the archives as both location and a practice. As location and practice, archives are a place-physical and virtual-where archival collections are organized, contained, preserved, and made accessible. Importantly, for my work as archivist collaborating with communities to collect multiple histories that

\footnotetext{
${ }^{1}$ Utilizing methodology of the oppressed as a 'deregulating system' is important in this project to radically interrogate the archives because disciplinary boundaries, bodily boundaries, definitional certainties, along with regulatory concepts of time will be challenged and unsettled.

${ }^{2}$ Carrillo Rowe and Licona urge feminist scholars and activists to break free from static identity practices that have served as the unexamined foundation of the feminist alliance base. As I posit, utilizing entrenched traditional archival practices--appraisal and description--without critical interrogation, risks reproducing the same exclusions that archivists seek to remedy by focusing on inclusion in collection policies and strategies.
} 
challenge dominant narratives, my consideration of the archives, then, must challenge the traditional archival paradigm as static structures of evidence and proof that continues to permeate archival discourse (Duranti 2007, 449; MacNeil 2011, 176). I recognize that archives are living; therefore, the archival body is comprised of bodies of knowledge that shift, change, and are always becoming (Gilliland 2010, 339).

\section{Normative/Normativity}

In the Oxford English Dictionary, normative is defined as 'establishing, relating to, or deriving from a standard or norm, especially of behavior' (OED online). Questioning practices and behaviors to unsettle and unhinge the power structures is key to my work in archival productions. Therefore, I suggest that certain archival practices, as normative, have become invisibilized through everyday use. Bodies and bodies of knowledge might also be considered normative through everyday performances. Nationstate formations are reliant on such normative structures and the production of good and bad citizens in order to keep bodies contained and in their places (Puar 2007, xxv). I am interested in how oral history productions for the archives, then, navigate between and, at times, fit into distinct formations of good and bad citizens, even good and bad archives. To consider the mediating that both interviewee and interviewer must traverse, I employ queer as a methodology of unhinging and challenging containment into such categories.

\section{Affect}

For this paper, affect indicates "nonconscious and unnamed, but nevertheless registered, experiences of bodily energy and intensity that arise in response to stimuli impinging on the body" (Massumi as quoted in Gould 2009, 19). I suggest that the coming together during the interview process affectively moves the participants in a multitude of ways that can influence how archives are produced, organized, and interpreted. Affect matters; its influence reaches through each and every archival engagement and through time.

\section{Politics of Respectability}

Politics of respectability, especially throughout the LGBTQ communities, represent a particular form of embodied normativizing strategies. According to Deborah Gould, 'respectability, on a straight society's terms, was the price for admission' (2009, 89). The politics of respectability, therefore, become the methods of assimilating differences into what is acceptable by the dominant 'straight society' along with self-regulating in order to be considered good members of the group. As a form of gatekeeping, it reinforces status distinctions and, within the archival bodies of knowledge where intimate and public come together, vulnerable spaces and silences are recognizable thus urging archivists to actively identify injustices and work with communities to reimagine possibilities for social justice.

\section{Embodiment \& Focus on (Un)Becoming}

I begin with the online Oxford English Dictionary definition of body as 'the physical structure of a person or an animal, including the bones, flesh, and organs' while also considering the body as the main part of something, which connects to the non-flesh 
archival structures and the organization of the bodies of knowledge. By embodiment, I mean the ways in which humans know and move in the world. I begin from Nikki Sullivan's and Susan Stryker's engagement with the concept of 'bodily being-in-theworld' (2009, xii). I, therefore, understand embodiment as a process. I particularly attend to those transdisciplinary literatures that focus on the (un)becoming, the simultaneous becoming and unbecoming, that influences the ways humans become culturally legible (Deleuze and Guattari, 1987, 88). I engage (un)becoming through the archives in order to recognize that bodies are never complete and always in processes of becoming.

\section{The Interview}

Drawing from my hands-on oral history productions, I recognize the bodies and bodies of knowledge-human and non-human histories and structures-that interact and inform one another throughout the oral history event from production through digital archival points of access. Considering the Arizona Queer Archives as the repository for the specific oral history interviews that I am utilizing to instantiate the archival affective multimodalities that work to contain, hold, and structure archival records and collections, the questions in these examples are tailored to initiate storytelling about lesbian, gay, bisexual, transgender, and queer identities, belonging, and longing for such spaces. The establishment of the Arizona LGBTQ Storytelling Project in 2008 and its migration and ongoing programming through the Arizona Queer Archives at the Institute for LGBT Studies make visible the importance of lived knowledges as historical record. Bodies are positioned to ask questions and answer questions with lived histories and knowledges always informing the interactions. The question and answer movements mediate and are mediated by varying degrees of intimacy between two people and with a video camera recording every detail for access through the archival online repository.

On 3 April 2010, with funding through the Institute for LGBT Studies at the University of Arizona, I conducted a daylong workshop with trans*3 ${ }^{3}$ identified individuals at Wingspan, the now defunct LGBT Community Center of Southern Arizona. As an archivist and oral historian committed to queer/ed practices, I structured the workshop around a participatory ethos to collectively create the list of questions that would be asked of participants. Eight of us gathered around the conference table. Conversations flowed as we discussed some of the issues faced in our daily lives especially those relevant to living as trans* in the state of Arizona where legislators passed bills that highly regulated bodies whether brown, queer, and gender non-confirming. ${ }^{4} \mathrm{We}$

${ }^{3}$ Trans has identified a trans man or trans woman through the dichotomous lens of gender whereas the term trans* is intended to suggest the ways that gender might be understood as incredibly diverse and, for me, something that is ongoing. As someone not interested in 'umbrella' terms to uncritically contain individuals, I remain critical of trans* as functioning like 'umbrella,' but am thinking further about its correlation to an aggregating technology used in coding. With this in mind, I will do archival work to reflect how records creators selfidentify.

${ }^{4}$ In 2010, the $49^{\text {th }}$ Arizona State Legislature started the work of regulating non-normative bodies through bills that have been proposed and passed since, such as SB1070 (the 'show me 
organized a set of questions to be understood as starting points in interviews with trans* identified participants to cover relationships among partners and lovers, families, medical doctors, housing, employers and co-workers, as well as lived histories and desires.

Being committed to sharing the skills and literacies of media production, I trained participants to set up the equipment for the interviews. Cameras were turned on. Headphones plugged in. Participants took their places, whether in front of the cameras or behind the cameras. Here I begin with the most important questions asked during this day of interviews: 'What kind of transgender are you? How do you define yourself?'

Responses are tethered to this moment in time. Camera timecode is timestamped to the media containing stories of how each interviewee recognized themselves within the spectrum of trans* identities. When the oral history interviews are accessed through the online digital archives website, this moment's interview engagement and storytelling is what marks the bodies-to include human as well as bodies of knowledge, histories, contexts, and technologies. For now, however, the responses are the bodily markers of interviewee, interviewer, and this date in history.

Allison, a friend and former co-worker of Michael's at the Southern Arizona Gender Alliance, SAGA, conducts his oral history interview. Both of them have worked for Wingspan and SAGA in a variety of capacities so they have a history with each other as well as the organization that works to support LGBT communities in the local Tucson area. Having a working relationship and certain intimate knowledge of one another makes the interview conversation seem easy and at times playful.

Allison: This series of interviews that we are doing is around transgender people. What kind of transgender are you? (Laughter)

Michael: Words I use to describe myself are F to M, Female to Male transsexual, trans man. I sometimes use the word queer or heteroqueer. Hetero-queer meaning I'm primarily focused on my interest in women, but at the same time, my life and all my culture and everything I do is pretty much in the queer community. Even if I'm dating women. I've also been known to date men. But "bi” doesn't really work for me. That's not really about trans, but it's just about how fluid everything is. Because "bi" is too limiting because that means that there are only two genders, and what about other people? So, transsexual F to $M$, trans guy, trans man, or just man.

The interviewee mediates the normative and non-normative in their storytelling techniques, especially in the ways that they understand themselves in relation to the interviewer, the camera, and the archives as one constituted by queer histories. Michael describes himself and offers narratives of what certain terms mean to him. He speaks

your papers' bill); HB2281 (the 'ban of ethnic studies' bill); the bathroom bill through which people must use the bathroom corresponding to their 'sex' on their birth certificates; and SB1062 'the anti-gay/religious freedom' bill. 
directly to Allison. As he understands gender to be more fluid, he highlights the ways that distinct uses of descriptors might foreclose possibilities of who he is and whom he might desire. Because the interviews take place within Wingspan, an organization that he is comfortable with, I sense a level of confidence in explaining fluidity. I question whether or not I would receive such ambiguous descriptions if I were to conduct the interview in another location that is unfamiliar to Michael. As I sit in the background and observe the storytelling, what becomes more obvious to me is the multiplicity through which people know, move, and exist. According to Nan Alamilla Boyd, queer oral histories have 'an overtly political function and liberating quality...' $(2012,1)$, especially for those involved in the interview process, but also for the archival body. As archivist and in consideration of these recordings for archival preservation and access, I recognize the possibilities that open up for the archives and ask: What influence will multiplicities in relation to time and space have on archival description?

Diana: Transsexual woman. More on the female side.

In Diana's interview, the feminine structures her mediation of the fuzzy line separating the public and intimate spaces of the interview process. She quietly responds to the interviewer while often glancing directly at the camera.

Diana: I can remember the times when...if somebody had caught me in clothes, I would have been petrified. Now I can't think of -I can't-I can't even think of those days or who that other person used to be. That other person is so far gone...

As the camera records every question and answer, Diana navigates through the terrain of past and present and her ongoing transitioning from male to female. She holds herself as Diana in the foreground while looking at her past self as 'that other person'-without a name, gender, and future. 'That other person' holds tight to and is tethered to the past that is Diana's, but unnamed and unmarked as such. However, Diana knows and embodies this past.

As an archival record, her oral history tells of 'body-based knowing' and the performative reiteration of gender in the telling and revealing of our bodies of knowledge and bodies of evidence (Butler 1993, 8). Boyd argues 'the physical presence of sexual or gendered bodies affects the oral history collaboration' (2012, 1-2) as interviewer and interviewee come together around a distinct set of questions and assumptions that move each separately through their own understandings of what becomes the archival record. The archives as bodies of evidence, therefore, also tells of body-based knowing and through reiterative archival practices. As oral history might be considered a social space with intimate and public potentials, a transformative event occurs as new knowledge is produced and lived knowledges emerge as valuable and valid truths.

Michael in turn interviews Alison. Alison gets comfortable in front of the 'Together We Are Wingspan' banner. In her oral history interview, she offers those of us in the room as well as visitors to the digital repository the distinct ways that she makes meaning. 
Michael: So, what kind of T are you?

\begin{abstract}
Alison: (Laughs) Well, I'm...I self-identify as a transsexual woman, um. I think that in the way that's descriptive of who I am and somewhat of the journey that I've been on, um, you know. I guess, one of my idols in the Trans community has been Kate Bornstein and on of the things that Kate and I agree on a lot is that, you know, our unique situation is a little different than people who were born to their sex of gender so I don't have all of the knowledge, the wisdom, the experiences that someone who is born female would have. I lived part of my life as a man, so um, I've transitioned with some medical enhancements so I'm transsexual.
\end{abstract}

Lived knowledges inform the oral history interview in both directions. In oral history interviewing, a narrative exchange occurs that can no longer be considered static. As interviewer, the ways one listens and pays attention to the queer details highlight for me the importance of developing the list of questions with participants to ensure relevancy to lives being lived. Additionally, the efforts of queer/ed oral history production intended for queer/ed archives must be necessarily critical about the work to be done to recognize and address power in the hands of 'authorized' oral historian and archivist. The oral history interview, in this case, instantiates the assembling parts-human and non-human - that mediate and are mediated during the telling of one's truths.

As the one who carries the oral histories that I have participated in, I recognize my responsibility to interpret and translate the affective states of becoming that each interviewee and interviewer navigate through. Normative social structures shape both interviewer and interviewee; such powerful structures move each into remembering or forgetting particular stories for the oral history recording. My stories and questions prompt distinct affective responses in the interviewee as they begin to respond. The politics of respectability function as a gatekeeping mechanism that nudges interviewees into storytelling that fits or subverts the dominant discourses about what and who LGBTQ individuals are. Stories might change. What remains are those nodes of affixed identity in this moment and in this context.

The oral history interview offers both a seemingly intimate exchange between two people but with a recording device that, through digital editing, compression, and streaming technologies, shares the exchange in an online public setting. With this in mind, I argue that the oral history interview affectively moves interviewees through creating and negotiating self at the interstices of time and space but always contingent and in relation to imagined future public digital dissemination. The oral history interview making its way into the archives for visitors to access also offers opportunities for interviewees to review their own individual stories. Boyd notes 'while the selfunderstood and often unspoken validation of narrators' subjective perspectives does not entail taking every recorded declaration of factual truth, it does require that researchers commit to listening carefully for what narrators' recollections reveal about their time and place in history' $(2012,5)$. The interview can, therefore, create a new vision and version of history, identity, and the concepts of belonging to the archival body. As evidences of lived knowledges, the storytelling techniques themselves might be 
recognized as the mediated practices that each storyteller embodies in order to move through transformative understandings of the contexts that structure lived histories as well as imagined ways lived histories might resonate in and out of the archives. The oral history interview conducted with non-normative multiply-situated peoples also crosses generational contexts and assumptions by making explicit connection to historical contexts.
Alison: ... and I got to California in the middle '60s and even at that point, I mean, I had always had the gender kind of confusion, the gender discomfort. I don't know what you...the technical term, disphoria, was always a thread throughout my life and I was aware of it at a core level.

\begin{abstract}
Alison traces the distinct naming categories as something that she embodied throughout her life but that failed to contain her. The oral history might effectively map the discursive violences that played out on non-normative peoples that were then further embodied by non-normative peoples. Moreover, the oral history 'necessarily disrupts historical paradigms that do not or will not acknowledge the existences of bodies, genders, and desires invisible to previous historical traditions' (Boyd, 5). Jesse, too, shares his experiences with fear of standing out as different and highlights the new experiences he is enjoying.
\end{abstract}

Interviewer: So, how has it been for you [...]now being a straight guy and having a girlfriend and going out in public?

Jesse: Very comfortable, yeah. I look forward to, um, you know, the little things like feeling paranoid about going to a bed and breakfast. You know, traveling. Going into restaurants and being stared at. It hasn't been happening as much and I don't think that it's as much of a physical change because I'm still a baby. I think it's my confidence and I think it's my attitude, you know, and my peace.

Interviewer: And your voice...

Jesse: My voice? (Laughs) Yeah, it was kind of deep before, so I got lucky on that. I did do the 'Donald Duck' thing for about two months and my brother loved that. So, I go by Donald occasionally. (Laughs)

Michael's question to Jesse: So what makes a man?

I hold onto this question without giving Jesse's answer. This pause-a temporary suspension-enriches the moment to consider the multitude of responses, especially considering those that may come from a room filled with transgender- and queeridentified individuals. This moment is latent with the urgency to recognize the structures in place that regulate gender-those same structures that have attempted to 
contain each interviewee in ways that held them captive in states of affective and unruly captivity. This pause. Oral histories and those made accessible in the queer/ed archives might work as guides for social justice rather than upholding dominant structures. In the archives, how might the oral history interview urge questioning of evidence and truth?

\section{The Archives}

The archives collects, preserves, and makes accessible the records from this day of oral history productions. Each interview offers intimacies experienced between interviewer and interviewee while the camera and recording technologies hold the space for public engagement. Through the archives and archival productions, the stories are tethered to history as a collective body but constituted by multiple histories and truths. Therefore, multimodal storytelling on and through digital video, which elicits perception through visual (seeing), aural (hearing), and haptic (combinations of 'tactile, kinesthetic, and proprioceptive, the way people experience though both on the surface of and inside our bodies' (Marks 2002, 2)) modes of human experience, creates a sense of culture and community that affectively moves and connects interviewees, interviewers, as well as those who access the records through the archives. Present and past overlap in the production while future permeates as the digital video begins to record for archival access at a later date. Temporality plays a role in the power of the oral history and function to engage the archives as a space of multiple histories through affective states of becoming that are related to emerging knowledge of the self. I suggest that the affective processes of mediating one's own story offers numerous detours that make up the many lived truths as part of (un)becoming.

I return to Michael's explanation of what 'kind of transgender' he is.

Michael: Words I use to describe myself are F to M, Female to Male transsexual, trans man. I sometimes use the word queer or heteroqueer...

As archivist, I am moved to question how I might most accurately label his interview for easy access through subject headings, keywords, and metadata to offer those access points for visitors to the archives. He offers numerous identities and shares his own clarification. His naming and consideration of fluidity are important for archivists working with oral histories as they instantiate the urgency of a fluid and dynamic archives to hold multiple histories.

The archives is traditionally conceived of as an evidential repository, which requires rigid structures in order to uphold community and bureaucratic trust (Cook 1997; Blouin 1999; and Duranti 2007). Cook suggests that archives work 'as agents for legitimizing such power and for marginalizing those without power' $(1997,18)$. The archives holds power to shape and mold distinct historical formations, often supporting the ideologies of those in power. Although postmodern notions ${ }^{5}$ have influenced such

\footnotetext{
${ }^{5}$ Historically, archival productions have been structured around paradigms beginning with the publication of The Dutch Manual in 1898 as the first widely accessed book of archival
} 
rigidity by questioning the traditional archival structures and offering a more open door experience about what and who crosses into the archives, the modern archival paradigm haunts the archives (Cook 2000). However, archives themselves become storytellers (Bearman 1989). Any understanding of fluidity, therefore, unsettles the archives and the archival paradigm that archivists continue to embody and actively deploy in their work; yet, the archival paradigm is changing (Gilliland 2010; Gilliland \& White 2009; McKemmish 2001; and Flinn 2011). With shifting notions of temporality from within the body of knowledge, the embodied archives is in the state of (un)becoming with unsettled and unsettling naming practices and procedures that make room for multidimensional histories (Lee 2015). As archivists and archival theorists are increasingly concerned about the adherence to master narratives, I consider temporality and embodiment as integral to challenging archival structures.

Interrogating chrononormativity in archival productions radically opens the archives to multimodal and multi-dimensional truths that challenge linear notions of history. Chrononormativity is 'the use of time to organize individual human bodies toward maximum productivity' (Freeman 2010, 3). Take the old playground rhyme, for example, ' $\mathrm{X}$ and $\mathrm{Y}$ sitting in a tree. K-I-S-S-I-N-G. First comes love. Then comes marriage. Then comes baby in the baby carriage.' As chrononormativity, such a sequence of events should not structure peoples and communities into a certain way of being and loving. In my archival work, I question temporality and my own need to attempt to insert linear or normative ways of knowing and interpreting records and collections. Pushing against chrononormativity challenges archivists and can be unsettling, but will benefit the archives so that it can hold multiple histories from everyday lives. Such an understanding of time, its productions and politics, might elucidate how archivists shape particular collections and bodies of knowledges within greater archival narratives.

As technologies and communities change in relation to one another, archives are collecting more multimodal records, which means that many 'new' and emerging media together with 'old' media are coalescing in the collections needing to processed, preserved, and made accessible. Through records and engagements within archives, humans are moved affectively. Moving towards an openness that elicits new lines of questions and understandings of records and their performative nature benefits the archives as bodies of knowledges in order to represent human and non-human records creators in relevant and meaningful ways.

\section{The Digital Access Points}

Users of the archives, too, are shaped by their assumptions and the hegemonic selfregulatory technologies as they access collections and make meaning of records through keywords and metadata searches. Utilizing Margaret Hedstrom's idea of interfaces (2002) as the 'spaces of the loci of power of the present to control what the future will know of the past' $(2002,3)$, Cook and Schwartz note that archives have always been at intersections of past, present, and future. Notions of navigating these interstices beg

standards. Terry Cook traces the positivist/modern paradigm from 1900 to approximately 1995 when the postmodern paradigm emerged through the shifting practices within archives to focus on the processes of archiving rather than the products of archiving. See Cook, 1997. 
archivists to be prepared and agile in responding to 'both continuity and change in society's concepts of, needs for, and uses of the past, memory, information, knowledge, for ultimately what is at stake is the relevance of archives in society, the power of the record, and the present strength and future vitality of the archival profession' (13).

The Arizona Queer Archives is accessible through its online digital repository. There one can access at least sixty digital video oral history interviews - all described through Dublin Core elements and some with transcripts still holding misspellings as they wait for member-checking processes. The website's home page does not give indication of what has been accomplished nor what archival work still awaits. The name 'queer' suggests a politics of sorts, especially when connected to 'Arizona'-the US state where brown, queer, gender non-conforming bodies are continually regulated. The politics of respectability circulate throughout the stories but will be interpreted through the visitor's own lived experiences and digital literacies. The home page welcomes one into its pages. There are no insides or outsides here, but a nonlinear interface that is porous and shifting (Laine 2006, 93), much like the oral history interview itself in which the fuzzy border between human eye contact and the lens of the camera is permeable and locatable by a glance. Time collapses as the moment becomes recorded as past--the recorded and archived history of life's histories told as history of this moment.

Mouse clicks pull the visitor into the list - text and image - of oral history interviews. The visual images enhance the descriptive information and suggest the technological emergence of shared spaces through which a distinct co-presence becomes embodied through an distinct intimacy with history. Information-seeking behavior suggests that one sits quietly with computer to experience-again through visual, aural, and haptic perception-the interviewee's oral history interview. The full body is integral in the engagement of handling archival records in order to connect past, present, and future. Experiencing storytelling through the computer screen and speakers/headphones creates an intimate space of reflection. Push play. One is engulfed in stories and might recognize the affective states of becoming as they unfold through the telling itself. Meanwhile, converging and diverging media and mediations create further listening, interpreting, and translating within the visitor that enable them to engage with affective networks. Body (un)becomes on the computer screen while body (un)becomes through experiencing the story and embodied storytelling processes that are displayed on that screen. Records as digital and material representations of lives being lived overlap and intersect through what one can touch and one can only haptically imagine in its virtual distribution. Multimodal records hold multiple historical evidences and affects. Cook emphasizes that archival research, in order to be relevant within archival theory and practice that is changing, should move the focus away from record and toward the 'creative act of authoring intent or functional context behind the record' $(1997,48)$.

Incorporating heterogeneous concepts of records-all of which can support evidence of processes and living-offers the means for archives to better support diverse worldviews, from those Western linear models of time to those that disrupt the Western model, but are relevant to communities that may already have distinct recordkeeping practices in place. Non-linear thought might open up dynamic spaces and time. Braidotti suggests 
'creativity and critique proceed together in the quest for affirmative alternatives which rest on a non-linear vision of memory as imagination, creation as becoming. Instead of deference to the authority of the past, we have the fleeting co-presence of multiple time zones, in a continuum that activates and de-territorializes stable identities and fractures temporal linearity. This dynamic vision of time enlists the creative resources of the imagination to the task of reconnecting to the past' $(2002,165)$.

Questioning time and space in these ways lends the archives legitimacy and relevancy to non-normative multiply-situated peoples, thus challenging the normative structures that have been used to oppress and further marginalize. Social justice prevails in these moments and spaces by promoting multiple historical narratives that subvert and challenge dominant power structures.

\section{Epilogue}

Recognizing and understanding the shifting paradigms and approaches to producing and consuming archives are integral to opening the archives in radical ways to support the ability 'to conceptualize alternatives, often improvised' (hooks 1996, 206). Queer/ed oral history productions demonstrate the mediated and mediating technologies and techniques of digital media and, importantly, of individual storytelling. From passive to subjective to complexly and contingently interconnected, the archivists benefit from inquiring into the historicity of the archives. Drawing from Laura U. Marks, I, too, propose that 'we cannot help but be changed in the process of interacting' (2002, xvi). Gathering bodies and bodies of knowledges while also being attentive to the processes of (un)becoming will influence the archives and its sustainability as spaces for remembering and forgetting for years to come and for the time being.

\section{References}

Bearman, D. (1989). "Chap VI: Recorded Memory and Cultural Continuity." Archival Methods: Archives and Museum Informatics Technical Report, No. 9.

Blouin, Jr., FX. (1999). "Archivists, Mediation, and Constructs of Social Memory." Archival Issues 24 no 2 101-12.

Boyd, NA and HN Roque Ramírez, eds. (2012). Bodies of Evidence: The Practice of Queer Oral History. New York, NY: Oxford University Press.

Braidotti, R. (2002). Metamorphoses: Towards a Materialist Theory of Becoming. Cambridge, UK: Polity Press.

Butler, J. (1993). Bodies That Matter: On The Discursive Limits of "Sex." New York, NY: Routledge.

Carrillo Rowe, A and AC Licona. (2005). "Moving Locations: The Politics of Identities in Motion," NWSA Journal 17, no. 2, 11.

Cook, T. (1997). "What is Past is Prologue: A History of Archival Ideas Since 1898, and the Future Paradigm Shift." Archivaria 43: 17-63. 
---. (2000). "Archival Science and Postmodernism: New Formulations for Old Concepts."

Archival Science 1, no. 1: 1-24.

Cook, T and JM Schwartz. (2002). "Archives, Records, and Power: From (Postmodern) Theory to (Archival) Performance," Archival Science 2: 1-19.

Deleuze, G and F Guattari. (1987). A Thousand Plateaus. Minneapolis, MN: University of Minnesota Press.

Duranti, L. (2007). "Archives as a Place." Archives \& Social Studies: A Journal of Interdisciplinary Research 1, no. 0: 445-466.

Flinn, A. (2011). The Future of Archives and Recordkeeping: A Reader. Edited by Jennie Hill. London: Facet Publishing.

Gilliland, AJ. (2010). "Afterword: in and out of the archives," Archival Science 10: 333343.

Gilliland, AJ. and K White. (2009). "Perpetuating and Extending the Archival Paradigm: The Historical and Contemporary Roles of Professional Education and Pedagogy," InterActions: UCLA Journal of Education and Information Studies, 5(1): 1-23.

Gould, D. (2009). Moving Politics: Emotion and ACT UP's Fight Against AIDS. The University of Chicago Press.

Halberstam, J and I Livingston. (2005). In a Queer Time \& Place: Transgender Bodies, Subcultural Lives. New York, NY: New York University Press.

Hedstrom, M. (2002). "Archives, Memory, and Interfaces with the Past." Archival Science 2 no. 102: 21-43.

hooks, b. (1996). "'Choosing the Margin as a Space of Radical Openness"' in Women, Knowledge, and Reality: Explorations in Feminist Philosophy. New York: Routledge.

Laine, T. (2006). "Cinema as Second Skin." New Review of Film and Television Studies, 4(2):93-106.

Lee, JA (2015) A Queer/ed Archival Methodology: theorizing practice through radical interrogations of the archival body. Dissertation.

MacNeil, H. (2011). "Trust and Professional Identity: Narratives, Counter-narratives and Lingering Ambiguities," Archival Science: 176.

Marks, LU. (2002). Touch: Sensuous Theory and Multisensory Media. University of Minnesota Press.

McKemmish, S. (1994). "Are Records Ever Actual?," in The Records Continuum: Ian

Maclean and Australian Archives First Fifty Years, ed. McKemmish and Piggott. Clayton, Asu,: Ancora Press, 187-203.

---. (2001). "Placing Records Continuum Theory and Practice." Archival Science 1: 333359.

Oxford English

Dictionary

online: http://www.oxforddictionaries.com/us/definition/american english/normative

Puar, JK. (2007). Terrorist Assemblages: Homonationalism in Queer Times. Duke University Press.

Sandoval, C. (2000). Methodology of the Oppressed. University of Minnesota Press.

Sullivan, N and S Murray. (2009). "Introduction: Originary Somatechnicity" in Somatechnics: Queering the Technologisation of Bodies. Ashgate Publishing. 
Winterson, J. (1997) Gut Symmetries, New York: Alfred A. Knopf, Inc.

Jamie A. Lee, Assistant Professor of Digital Culture, Information and Society in the School of Information at the University of Arizona, attends to critical archival theory and methodologies, multimodal media-making contexts, storytelling, bodies, and ongoing analyses of the ways archives and bodies are mutually constitutive. Her work is intricately woven through the intersections of archival studies, media studies, digital and visual culture, and the body. As archivist, Lee founded the Arizona Queer Archives applying the Queer/ed Archival Methodology that she has been developing. As an award-winning social justice filmmaker, Lee's work has screened on PBS, Free Speech TV, and at film festivals and conferences throughout North America and Europe. She presented at the 2008 Women's World Congress in Madrid, Spain and was the keynote speaker at the 2009 New Directions in Critical Theory Conference.

Email: jalee2@email.arizona.edu 